\title{
ANATOMÍA DE LA MONSTRUOSIDAD: LA FIGURA DEL MONSTRUO COMO OBJETO DE LA MIRADA MÉDICO-ANATÓMICA MODERNA
}

\author{
Joaquin Fortanet \\ Universidad de Zaragoza \\ fortanet@unizar.es
}

Recibido: 22 abril 2014; Aceptado: 3 de octubre 2014.

Cómo citar este artículo/Citation: Fortanet, Joaquin (2015), "Anatomía de la monstruosidad: la figura del monstruo como objeto de la mirada médico-anatómica moderna", Asclepio 67 (1): p088. doi: http://dx.doi.org/10.3989/asclepio.2015.14

RESUMEN: Este texto plantea un análisis de la sustitución de la categoría médica de monstruo por la de hermafrodita. Para ello, se basa en el desarrollo de la anatomía humana en el siglo XVI y en el estudio de la relación fisiológica de los órganos del cuerpo a partir del XIX. Se supondrá como necesaria la investigación anatómica cartesiana y su reflexión sobre el cuerpo para poder abrir el camino a la mirada fisiológica sobre la vida como preludio de la medicina legal y social.

PALABRAS CLAVE: Monstruo; Anatomía; Descartes; Hermafrodita; Medicina.

\section{MONSTROSITY'S ANATOMY: THE FIGURE OF THE MONSTER AS THE OBJECT OF A MODERN MEDICAL-ANATOMICAL LOOK}

ABSTRACT: This paper presents an analysis of the monster category on medical research in the modernity. This analysis is based on the development of human anatomy in the sixteenth century and in the study of the physiological relationship between body and organs in the XIX. The Cartesian anatomical research and the naturalization of monster category will open the way to the physiological view of life as a prelude to legal and social medicine.

KEY WORDS: Monster; Anatomy; Descartes; Hermaphrodites; Medicine. 


\section{EL MECANISMO DEL ALMA}

Desde el momento en que el Renacimiento inicia el proyecto humanista encaminado a fundar el saber en el ser humano, la categoría de monstruo planea por los diferentes saberes como el elemento excesivo que no puede ser contenido en la base fundamental de las ciencias. Será la medicina, concretamente la anatomía humana, una de las primeras disciplinas encargadas de establecer la demarcación entre persona y monstruo a partir de características anatómicas que permitan una definición científica del cuerpo humano. Para encontrar el sentido de la irrupción de la categoría de monstruo en el saber científico del siglo XVI y XVII, no sólo debemos atender a los tratados de anatomía de la época, sino también al progresivo alejamiento entre alma y cuerpo que, desde una filosofía ya notablemente secularizada, se estaba llevando a cabo simultáneamente a la construcción teórica del sujeto moderno.

Los grandes tratados sobre monstruos del siglo XVII llevados a cabo por médicos y cirujanos de la época nos muestran toda una batería de deformidades anatómicas investidas con el componente de lo maravilloso (Daston, Park, 1998). Son extraordinarias, responden en numerosas ocasiones a lo sobrenatural y atrapan la mirada fascinada de nuestra modernidad. Será la época ilustrada la encargada de secularizar al monstruo, de neutralizar completamente su componente fascinante (Canguilhem, 1980) a través una taxonomía teratológica de la anormalidad anatómica (Saint-Hilaire, 1832). Sin embargo, consideramos aquí que la llustración completa un proceso que se prefigura en el nacimiento de la razón moderna y, más concretamente, en el establecimiento de la subjetividad cartesiana. Es el esfuerzo cartesiano por distinguir la mente razonable del cuerpo donde podemos entrever por primera vez un comienzo del proceso de naturalización de la deformidad a través de la anatomía mecanicista, que se opone a la mirada maravillada fundada en lo sobrenatural (Boaistuau, 1561). Desde los primeros tratados modernos sobre monstruos, como el de Lycosthenes de 1557 o el de Boaistuau en 1561, que oponían la maravilla de la diferencia anatómica al saber médico propiciado por las disecciones, hasta el tratado de Saint-Hilaire en 1832, en el que se identifica monstruosidad con anomalía naturalizada, media toda la historia subterránea de las miradas y los enfrentamientos, de las proximidades y lejanías entre los monstruos y el saber que los define. Es por ello por lo que en este texto se tratará de dar cuenta de algunos pasos esenciales en esta historia de la monstruosidad que nace en el momento en que el saber médico en ciernes la toma por objeto teórico y muere en el XIX, en el momento en que la medicina destila su verdad epocal: el hermafrodita.

\section{ABRIR EL CUERPO}

A lo largo del siglo XV, el Renacimiento promueve una conexión entre arte, filosofía y medicina orientada al conocimiento del cuerpo humano. El interés por los cadáveres y sus disecciones ya no es algo propio de médicos excéntricos que debían acudir al delito para hacerse con un cuerpo muerto, generalmente conseguidos con unas pocas monedas. Pese a que la práctica de la disección prosperaba en el exterior de colegios y universidades desde el año 1300, rituales, cultos, autopsias con fines sanitarios u obstréticos (Park, 2006, p. 11), las disecciones académicas comienzan a cobrar protagonismo respondiendo, por una parte, a un interés artístico naturalista consistente en el conocimiento visual del interior del cuerpo humano. Por otro lado, la medicina anatómica, que tradicionalmente había bebido de los hallazgos fisiológicos de Galeno a partir de disecciones animales ${ }^{1}$, comienza a girar su mirada hacia la posibilidad de comprender el mecanismo íntimo del cuerpo humano, con un particular interés por el cuerpo femenino: "L'élucidation des secrets des femmes devint l'un des principaux objetifs des médecins» (Park, 2006, p. 20). Las primeras disecciones humanas documentadas y legales las encontramos en Italia a partir del siglo XIV- Mondino di Luzzi- aunque será a lo largo del siglo XV, de la mano de los maestros anatomistas de la escuela italiana, cuando encontremos una mayor profusión e interés de las autopsias, muchas veces públicas, realizadas en teatros anatómicos, algunas veces desmontables, en los cuales incluso se cobraba entrada, refrendando así su carácter espectacular.

A. Benedetti, B. De Carpi, G. Zerbi y Benivieni (Nogales, 2004, p.16) desarrollaron su investigación anatómica mostrando la importancia de la autopsia y la disección a la hora de comprender el fundamento del cuerpo, abriendo al mismo tiempo un terreno fascinante, anteriormente vedado y oculto, que era vivido como una ventana a lo desconocido, mezcla de sangre, muerte y ciencia: «La disección pública fue durante toda una época un espectáculo a la vez instructivo y edificante, que se efectuaba en invierno para retrasar la putrefacción: el cadáver siempre debía ser el de un criminal ejecutado» (Porter, 2004, p.100).

Sin embargo, la fascinación primera se va desplazando hacia el interés puramente científico. La mirada que anteriormente era una mirada fascinada, mezcla de horror y curiosidad, va dejando paso a una visión objetiva, el ojo científico se posa sobre el cadáver haciendo abstracción de la sangre y bilis, contemplando cuantitativamente los órganos, humores, líquidos y conductos a través de los cuales el cuerpo que éramos funcionaba como una fábrica. De tal suerte que a partir del siglo XVI la publicidad de tales disecciones comienza a caer en desuso. La disección pasa a ser un 
elemento científico que debe realizarse únicamente para ojos versados en la ciencia médica. Su significación comienza a medicalizarse.

Vesalio es, sin duda, la principal figura italiana del saber médico del siglo XVI. Su contribución a la anatomía sólo fue comparable al tratado de Galeno. La influencia de su trabajo se dejó sentir en toda Europa, llegando a Valencia, Alcalá y Salamanca a través de dos de sus discípulos, Pedro Jimeno y Luís Collado (García, 1976, p.55).

Una revolución anatómica tal no era posible sin la práctica cotidiana de la disección, que permitió a Vesalio acercarse como nadie lo había hecho al cuerpo humano, con una mirada que separa y objetiva al cuerpo, concebido ahora como fábrica. Los 300 grabados de la gran obra de Vesalio, De humanis corpori fabrica, publicada en 1543, sintetizan esa particular mezcla renacentista entre hermetismo y cientificismo; el horror y lo sagrado conviven con el rigor apasionado por la descripción detallada, por el patetismo de las posturas, por la desolación de los rostros. Imposible acercarse a los grabados de los desollados de un modo neutro. Porque, justamente, el rigor científico por la descripción unido a la desolación por la muerte que provoca un cadáver sajado, va a reforzar una mirada que "olvida metodológicamente al hombre para considerar tan sólo su cuerpo» (Le Breton, 1990, p. 52). El cuerpo se separa definitivamente del ser humano al que pertenecía, abriendo una brecha entre anatomía y la antigua fisiología, entre estructura y función según el biologismo aristotélico. La mirada anatómica lo toma como una totalidad ajena a la mente, como una fábrica de cálculos y tumores, de circulación y músculos, en definitiva, como una sustancia que requiere un acercamiento epistemológico radicalmente diferente a la mente. El cuerpo entra de lleno en el terreno de la extensión, del mecanismo. De ahí el conocido reproche que Vesalio realiza a Galeno y a todos aquellos que rechazan el arte anatómico de la disección en su Prólogo (Vesalio, 1960):

el único modo de conocer la fábrica corporal es a través de la observación directa. No hay nada en el cuerpo que pueda ser comprendido por recurso a instancias ajenas al mismo cuerpo. Ese resto ajado del ser humano que es el cuerpo debe comprenderse necesariamente desde el mismo cuerpo.

Cuando la Fábrica insistía en el imperativo metodológico de que la estructura humana sólo puede observarse en el hombre [...] Vesalio presentaba una estructura del hombre en la que el hombre mismo, y sólo él, era su referencia y su medida [...] Vesalio hacía del cuerpo humano el único documento verídico sobre la fábrica del cuerpo humano. Al interesarse en la anatomía del perro o el mono a la vez que la del hombre, lo hacía para confirmar la diferencia de este último (Canguilhem, 2009, p. 32)
Tanto las láminas de la Fábrica como al mirada anatómica de Vesalio nos emplazan ante la superación del paradigma renacentista, iniciando el camino hacia una nueva subjetividad en la cual se hace imperativo una definición precisa de la materia corporal que dé cuenta de la situación de la mente y el cuerpo en un universo que ha perdido las referencias escolásticas tradicionales y debe guiarse a través de una nueva razón científica. Sin embargo, no basta con la mirada anatómica, no basta con la descripción fascinante de los mil nervios que pueblan el interior de nuestra fábrica-cuerpo. El mecanismo debe ser explicitado totalmente, objetivamente, científicamente. La retirada de la visión pública de las disecciones responden a ese envite del saber: afilar la mirada, comprender el mecanismo-cuerpo, despojarlo de todo excedente significativo, convertirlo en resto, en una máquina de huesos y carne. Para ello se precisa, primero, dar el paso de la observación a la definición programática de qué es un cuerpo. Y, en ese paso metodológico fundamental de la anatomía, es dónde se nos aparece como central la categoría de monstruo a partir del siglo XVI.

\section{MONSTRUOS, TERATOLOGÍA Y SEXUALIDAD}

En 1585 Ambroise Paré, uno de los principales cirujanos de su época, publica uno de los tratados más célebres sobre la monstruosidad: Monstruos y Prodigios. Su obra se nos aparece como un repertorio fantástico de las monstruosidades del cuerpo, de los defectos anatómicos que forman el elenco de lo anormal anatómico. Por primera vez, la mirada médica de un cirujano se enfrenta a la tarea sistemática de categorizar la anormalidad patológica. No era la primera vez que los monstruos eran objeto de la literatura científica.

De hecho, durante el siglo XVI aparecen numerosos textos que hacen del monstruo su objeto principal, animados por una suerte de fascinación colectiva que se extenderá a lo largo del siglo entre los ambientes intelectuales alemanes y franceses, particularmente en aquellos influenciados por la influencia evangelista, por la reforma luterana o por el círculo de Wittenberg (Vega, 1995, p. 226). Sería posible establecer una categorización de los tratados sobre la monstruosidad dependiendo del modo de acercamiento al fenómeno. Así, los tratados modernos de la primera mitad del siglo XVI, desde el De Prodigis de P.Vergilius en 1531 hasta el primer Wunderzeichen de Fincelus en 1556, constituirían un primer grupo que se definen por el intento de interpretar el prodigio sobrenatural que es el monstruo. La interpretación es, en todos los casos, sobrenatural, siguiendo el esquema clásico que, desde la Edad Media con Isidoro de Sevilla y Tomás de Aquino, había concebido al monstruo o bien como un signo que advierte del porvenir o como un signo del diablo, en todo caso ligado a lo sobrenatural (David- 
son, 2004, p. 156). Un segundo grupo de tratados se inauguraría con el Prodigiorum ac ostentorum chronicon de Lycosthenes en 1557, contaría con los textos de Boaistuau y Paré y se definiría como un intento de compilación de las figuras monstruosas que comienza a utilizar los caminos médicos para iniciar la naturalización de lo monstruoso. Un tercer grupo de tratados, que ahondan en la naturalización de la monstruosidad, se inaugura con la obra Thaumatographia naturalis, del naturalista polaco J.Jonstonus en 1632. Estos estudios desembocan, ya en 1832, en la última figura de los tratados monstruosos, ya plenamente naturalizados y por ello mismo condenados a su propia desaparición: el Traité de Tératologie, de I. G. Saint-Hilaire. En España, destacan los tratados sobre monstruos de A. Torquemada, EI Jardín de Flores Curiosas, en 1575, Curiosa y oculta filosofía, de E.Nieremberg en 1643, El ente dilucidado, de A.Fuentelapeña en 1643 y Desvíos de la naturaleza o tratado del origen de los monstruos publicado en Lima por el Dr. José Rivilla y Bonet en 1695. Todos ellos participan de la ambivalencia entre lo sagrado y lo anatómico que Lycosthenes expresa en su obra. Ambivalencia que será combatida parcialmente por las consideraciones médicas que se suceden de la difusión de la traducción española en 1603 de Monstruos y Prodigios de Paré.

La clave de los cambios de modulación de esta historia de los tratados monstruosos es, sin duda, el proceso de naturalización y la pérdida de protagonismo de lo maravilloso que sufre el tratamiento de la monstruosidad. Sin embargo, no debemos atribuir dicha naturalización a un progreso de la razón fruto de la evolución del ser humano y de su conocimiento. Otros elementos intervienen en este particular juego de la monstruosidad en el que se dan cita la medicina, la anatomía, el alma, la sexualidad y la normalidad. Es por ello por lo que se tratará de ajustar convenientemente los motivos y los actores principales en este progresivo borrado y quizás transformación de la figura del monstruo en el universo del saber.

Uno de los primeros tratados modernos que intenta establecer un compendio de las monstruosidades es el de Pierre Boaistuau de 1561 quien, en su Historias Prodigiosas explicita el vínculo clásico y medieval entre el monstruo y lo maravilloso que recorre en mayor o menor medida la modernidad hasta la llustración. Boaistuau explicita su negativa a que la posibilidad de que lo monstruoso sea explicado a través del saber anatómico y mecánico, inscribiéndose en la línea de Lyconsthenes, catalogando lo maravilloso y sospechando de quienes intentan reducir su signo fantástico a mera razón:

II [Boaistuau] critiquait les médecins «qui se sont souvent trompés en la dissection de la fabrique du corps humain» et rappelle que "parce que notre sujet est les prodiges, nous ferons fin de cette matière»[11]. L'approche matérialiste est une "laïcisation» et une naturalisation des naissances monstrueuses qui justement s'attachera à la «fabrique du corps humain» et de l'embryon afin d'en évacuer la dimension prodigieuse (Wolfe, 2008, p. 56).

Será Ambroise Paré, pocos años después, quien comience a establecer la primacía de la mirada médica sobre el monstruo. Los conocimientos anatómicos ya se encuentran lo suficientemente desarrollados como para ostentar un saber descriptivo del mecanismo del cuerpo y, precisamente, esa mirada positiva sobre la fábrica corporal es lo que permitirá una categorización de la anormalidad patológica que Paré ha contemplado como objetivo de su trabajo. Sin embargo, debido principalmente al divorcio vesaliano entre anatomía y fisiología, la clasificación de la monstruosidad debe realizarse siguiendo un criterio puramente anatómico, evitando las referencias a la fisiología galénica. Nada hay fuera del cuerpo que explique el cuerpo. Salvo Dios, el demonio y la imaginación:

Las causas de los monstruos son varias. La primera es la gloria de Dios. La segunda, su cólera. La tercera, la cantidad excesiva de semen. Cuarta, su cantidad insuficiente. Quinta, la imaginación. Sexta, la estrechez de la matriz. Séptima, el modo inadecuado de sentarse de la madre que, al hallarse encinta, ha permanecido demasiado tiempo sentada con los muslos cruzados y oprimidos contra el vientre. Octava, por caída, o golpes causados a la madre. Novena, debido a enfermedades hereditarias o accidentales. Décima, por podredumbre o corrupción del semen. Undécima, por profusión o mezcla de semen. Duodécima, debido al engaño de los malvados mendigos itinerantes. Y, decimotercera, por los demonios o diablos (Paré, 1987, p.22)

Paré divide a los monstruos en dos grandes grupos. Lo realmente significativo de esta clasificación es que el criterio de ordenación parece responder a causas o bien naturales o bien sobrenaturales. Sin embargo, si profundizamos en mayor medida en el particular bestiario de Paré, nos encontramos con que los tipos de monstruos pueden clasificarse, más allá de sus causas sobrenaturales, en función de la particular mezcla que los afecta.

Observemos algunos de los monstruos referidos por Paré: potro con cabeza humana, monstruo asombroso (con alas en lugar de brazos), niña con dos cabezas, dos gemelas pegadas, un hombre de cuyo vientre salía otro, niñas unidas por la frente, hombre con cabeza en el vientre, cerdo con cabeza de caballo, mujeres encintas de 20 hijos, hermafroditas, mujer que se convierte en hombre, hombre sin brazos, niño con rostro de rana, niño con cuerpo de perro... 
Resulta evidente que la noción de mezcla atraviesa esta clasificación, $y$, de hecho, parece que la idea de Paré a la hora de pensar una causa natural de la monstruosidad apunta a ello. En su clasificación pueden observarse dos tipos de mezcla: entre seres humanos y entre seres humanos y animales. La mezcla con animales responde, según Paré, a elementos sobrenaturales cuya causa es atribuida a lo divino o demoníaco- y que forma parte de la tradición religiosa de la época. Todavía Paré no puede obviar el elemento de lo maravilloso. La fascinación que ejerce el monstruo en el siglo XVI empaña la mirada positiva de la ciencia médica que, sin embargo, trata de avanzar caracterizando aquello que se le escapa (Ancet, 2006, p.41).

A pesar del componente fantástico de la monstruosidad, Paré nos ofrece un intento de abordar el exceso propio de la caracterización del monstruo: la mezcla entre seres humanos requiere una explicación natural, esto es, anatómica. Ya sea en la procreación o en la gestación, la causa que produce la mezcla entre seres humanos es perfectamente reconocible e incluso objetivable.

Desde este punto, la mirada anatómica de Paré va a centrarse en definir estos casos extraordinarios, tomando un hecho singular que resulta altamente significativo para la nueva mirada médica: el hermafroditismo. La monstruosidad que pasa a ser objeto de los tratados del siglo XVI y XVII es aquella que pone en cuestión no sólo el orden anatómico humano, sino el orden del saber que se está constituyendo en torno a la figura del sujeto. El verdadero monstruo es aquel que deja sin respuesta, que interrumpe el funcionamiento de los saberes encargados de fundar el sujeto moderno, de regular las conductas posibles del ser humano. Es aquel que introduce lo sobrenatural en el decurso natural, privando de suelo a las reglas humanas establecidas sobre las bases de la naturaleza humana (Foucault, 2007, p. 69). Uno de los casos de mezcla humana que la mirada anatómica eleva a categoría central de la monstruosidad va a ser el hermafrodita. Hasta el siglo XIX, podemos convenir que, en líneas generales, los hermafroditas pertenecen al ámbito de lo monstruoso:

En la Edad Clásica se privilegia un tercer tipo de monstruosidad: los hermafroditas. Alrededor de éstos se elaboró o, en todo caso, empezó a elaborarse la nueva figura del monstruo que va a aparecer a fines del siglo XVIII y funcionará a principios del XIX (Foucault, 2007, p.73).

Hay, no obstante, que conceder excepciones a esta línea interpretativa, como son aquellas pertenecientes a la línea teórica galénica, (Daston, Park, 1998, pp. 11-19) en la que se mantenía la idea de que el hermafroditismo pertenecía al ámbito natural y no monstruoso (Laqueur, 1994, pp. 23-37).
El hermafrodita es tratado ampliamente en la obra de Paré, identificando diferentes tipos de hermafroditismo, todos ellos contemplados bajo la noción de mezcla entre hombre y mujer. Esta mezcla va a convertirse en una de las transgresiones más complejas de manejar por parte de los saberes de las ciencias humanas que van desarrollándose. El derecho no puede dar cuenta de lo extraordinario de la mezcla, la misma anatomía parece quedarse muda ante la posibilidad de un ser que represente la unidad de ambos sexos. Será preciso que la anatomía profundice en el mecanismo humano, que comience a indagar en el carácter más íntimo de nuestra fábrica, que intente naturalizar al monstruo a través del análisis de la sexualidad: «Le monstre est à la fois l'effet d'une infraction à la règle de ségregation sexuelle spécifique et le signe d'une volonté de perversión» (Canguilhem, 1980, p. 174). Podemos observar el progresivo hundimiento en el análisis de la sexualidad por la utilización de todo un nuevo vocabulario antes prohibido. La normalización del vocabulario sexual en los tratados médicoanatómicos responde a este hundimiento de la mirada analítico-quirúrgica en los usos y costumbres de la sexualidad de la fábrica del cuerpo. Hasta tal punto la mirada médica se hunde en la sexualidad que, tal y como nos refiere Paré, es el cirujano, por primera vez y anticipando la medicina legal posterior, el encargado de elegir el sexo del hermafrodita: "Los médicos y cirujanos experimentados y entendidos pueden discernir si los hermafroditas son más aptos para ostentar y utilizar un sexo u otro» (Paré, 1987, p. 38).

El criterio utilizado pasa por analizar los caracteres anatómicos del hermafrodita como el tamaño de los sexos, la voz y el aspecto, a partir de los cuales el cirujano debe decidir qué sexo es el predominante, llegando incluso, en ciertos casos, a anular la posibilidad de la práctica sexual con el sexo elegido a través de la cirugía (Paré, 1987, p. 39). Sin embargo, el cirujano no ostentaba el papel que posteriormente se le concederá y, en múltiples casos como los de sexo dudoso, se ponían en marcha mecanismos establecidos por el derecho canónico a través de lo cuales las autoridades eclesiásticas determinaban un sexo provisional que el hermafrodita debía respetar (Vázquez, Cleminson, 2013, p. 32).

Si observamos a lo largo del siglo XVI y XVII la bibliografía dedicada al tema, nos encontramos con una profusión de los análisis anatómicos y médicos sobre los hermafroditas. A la publicación por Caspar Bauhin de su De hermaphroditorum monstrosorumque (Bahuin, 1600), donde atribuye las causas del hermafroditismo a errores en la unión sexual, le siguen los tratados de J. Schenk (1608), y de F. Liceti (1616), que darán pie a toda un nuevo modo de observar el fenómeno de la monstruosidad en el cual el interés por la monstruosidad sexual y los nacimientos mostruosos 
perfilarán el camino posterior de la mirada médica sobre la sexualidad reproductiva y, por lo tanto, el fin de la categoría monstruo como elemento central en el XIX. Será el tratado de I. Geoffroy Saint-Hilaire, Traité de Tératologie, en 1832, el último de los intentos de cartografiar la anormalidad según los dictados de la monstruosidad, a través ya de una explicación plenamente positiva y científica. A medida que avanza la naturalización y consiguiente desaparición del monstruo, el hermafrodita es rescatado desde una mirada paralela y oblicua: la de la medicalización sexual.

Hasta su fin, la monstruosidad representó para médicos, cirujanos y anatomistas un enigma en el que se jugaba tanto la bondad de Dios como la lógica de la ley natural y el orden de lo humano. La disección de monstruos fue practicada desde 1530 hasta mediados del XVII, únicamente sobre cuerpos hermafroditas o dobles. El hermafrodita, el monstruo doble, objeto de fascinación durante siglos, fue objetivado a través del bisturí, intentando hallar una solución anatómica a un nuevo problema que en siglo XVII se iba abriendo paso una vez el cuerpo queda anatomizado. Las disecciones y experimentación médica sobre los monstruos se extendió, fomentando el intento de reducir los componentes maravillosos y fascinantes de la monstruosidad. El monstruo se convierte, progresivamente, en objeto enigmático de la investigación médica (Tort, 1980), pues en él se juegan la amplitud y el diseño de las definiciones de normalidad, sexualidad y reproducción, hasta llegar a desaparecer como objeto, disuelto en el cruce de miradas positivas e iluminadoras del saber.

Pero en el siglo XVII, el problema no se planteaba en estos términos. Era más urgente y más próximo, de bordes gruesos que irán perfilándose. El monstruo era un cuerpo anormal, y, en mecanicismo, nos podía ofrecer alguna cifra de la conexión entre cuerpo y alma. Las monstruosidades, extravagancias maravillosas del orden natural, nos ofrecían todo un campo de experimentación para comprobar los avances del saber anatómico. El monstruo nos lleva al cuerpo, el cuerpo al alma y el alma a la vida misma.

\section{CUERPO, ALMA Y MECANISMO}

En 1643 Descartes responde a una carta de la princesa Elisabeth afirmando que, lamentablemente, en su obra no se ha podido ocupar lo suficiente del cuerpo, habiéndose centrado, quizás en exceso, en hacer comprender el carácter de la mente y en probar la distinción entre sustancias (Descartes, 1988, p. 8). Sin embargo, pese a que Descartes no haya tratado hasta entonces el cuerpo de un modo sistemático, no podemos afirmar que haya sido desatendido, sino todo lo contrario. En sus cartas a Mersenne de 1930, Descartes afirma haber comenzado los estudios y la práctica anatómica (Descartes, 1897a, p. 137) con el fin de intentar comprender totalmente el mecanismo del cuerpo, esperando aplicar dichos conocimientos a la tarea médica de prolongar la vida y encontrar remedios a las enfermedades - entre ellas, a la infección de piel que padecía el propio Mersenne.

En la quinta parte del Discurso, Descartes menciona un «tratado, que algunas consideraciones me impiden publicar». Dicho tratado es El Mundo o Tratado de la luz, escrito en 1633, en el cual se trata particularmente el tema del hombre en tanto res extensa. Evidentemente, tal y como Descartes menciona en las Cartas a Mersenne de fin de noviembre de 1633, febrero de 1634 y abril de 1634, las consideraciones que le impedían publicar tal tratado eran la condena de Galileo y la creciente suspicacia por el mecanicismo. Descartes nunca publicará esta obra en vida - se publicó en 1664. Pero supone un documento privilegiado para poder observar el análisis del cuerpo que Descartes realiza siguiendo los principios del mecanicismo y aplicando el saber anatómico - experimental- que había adquirido recientemente. Posteriormente, Descartes, en la etapa del final de su vida, escribirá su Descripción del Cuerpo, el Tratado de las pasiones del alma, la Generationem Animalium, y los breves textos Remedia Vires Medicamentorum, y Anatómica (Descartes, 1897b). Vemos entonces que el interés cartesiano por el cuerpo se extiende a lo largo de su obra, desarrollando una reflexión anatómica mecanicista que abrirá el camino a la mirada anatomofisiológica moderna (Peset, 1973, p. 219).

El Tratado del Hombre aplica los principios físicos generales de la extensión al cuerpo humano. El cuerpo humano es analizado sin recurso al animismo aristotélico, pensado a la manera de un autómata cuyo juego de elementos internos mecánicos produce todas las funciones corporales. Así, Descartes anula las referencias a las partes de alma aristotélicas que producían el movimiento y la vida misma (Descartes, $1897 b$, p. 202). Descartes no atribuye ningún principio exterior al cuerpo. La sustancia extensa, autosuficiente y ontológicamente independiente, participa de la naturaleza mecánica de la física y, por lo tanto, la fisiología del cuerpo humano, las funciones de los órganos, se explican a través de la mecánica interna y la disposición de los órganos. Incluso el principio de movimiento y el principio de vida son refractarios a la intervención del alma sobre el cuerpo: dependen del propio mecanismo corporal.

Es sin duda el saber anatómico el que le permite a Descartes aplicar el mecanicismo al cuerpo, encontrar sus propias leyes a partir de los movimientos involuntarios, su particular mecánica de vida en el fluir de la sangre y los llamados espíritus, semejantes a corrientes nerviosas. A partir de estas consideraciones, Descartes 
va a plantearse diversos problemas: la nutrición, el movimiento y las percepciones. A todos estos problemas responderá con explicaciones mecánicas fruto de la observación y experimentación anatómica. En cuanto a la nutrición, los alimentos son fermentados en el estómago a través de un proceso químico y mecánico de agitación de partículas (calor). Descartes explica el movimiento de la sangre a través del modelo circulatorio de Harvey, de la respiración y de la regeneración y crecimiento del cuerpo. El sistema nervioso sigue un modelo hidráulico, semejante al circulatorio, y para Descartes, en conexión con el cerebro, es el causante del movimiento del cuerpo, tanto de los involuntarios (que únicamente se refieren al cuerpo) como de los voluntarios (que requieren la conexión alma-cuerpo a través de la glándula pineal, la cual se comunica con el cuerpo a través del mismo fluido nervioso). Por otra parte, las percepciones son explicadas siguiendo el modelo clásico de la linealidad de transmisión de estímulo entre los órganos sensibles y la glándula pineal, la cual comunica al alma las informaciones captadas por el cuerpo. La glándula pineal es afectada por las sensaciones transmitidas por los espíritus, que a su vez son informados por los órganos perceptivos.

La anatomía le ha permitido a Descartes aproximarse a una explicación mecánica del funcionamiento del cuerpo. Sin embargo, en su afán por evitar las explicaciones fisiológicas que remiten a instancias ajenas al puro mecanismo, el cuerpo ha quedado reducido a un resto, a un autómata ajeno a la subjetividad, a un elemento más de la naturaleza extensa. Se ha provocado un desplazamiento tal entre la mente y el cuerpo que Descartes se enfrentará en sus obras ulteriores a otra cuestión: el problema de la generación de la vida, el cual esconde otra pregunta mucho más incómoda para el pensador que más lejos llevó la mecánica fisiológica: la pregunta por la vida misma. De la anatomía, entonces, Descartes abrirá la posibilidad de la pregunta por el motor de la vida, a través de las relaciones entre anatomía, fisiología y biología (Roger, 1963).

\section{SANGRE, ORGANISMO Y VIDA: LA ANATOMÍA EN MOVIMIENTO}

En el capítulo 65 de su Crítica del Juicio, Kant pone en marcha la tarea de distinguir entre mecanismo y organismo. Su distinción será de suma importancia, pues apunta a la misma cuestión en la que va a desembocar la investigación cartesiana: la generación y la vida:

Un organismo, pues, no es sólo un máquina, pues ésta no tiene más que fuerza motriz, sino que posee en sí fuerza formadora y tal que la comunica a las materias que no la tienen (las organiza), fuerza formadora, pues, que se propaga y que no puede ser explicada por la sola facultad del movimiento (el mecanismo) (Kant, 1999, p. 346)
Generar vida es aquello que demarca la separación entre organismo y mecanismo, aquello que nos permite elevarnos por encima del autómata y suponer que en el cuerpo humano hay elementos que no pueden ser explicados desde el modelo mecánico de la fábrica. Sin embargo, para Descartes la explicación mecanicista de la vida pasa por desvelar los enigmas de la generación de la vida a través de la cartografía estática de la anatomía humana. Será, como veremos, necesario el hundimiento cartesiano en el problema de la Generatio para que la anatomía se ponga en movimiento a través de la fisiología.

La formación de la vida desde el punto de vista cartesiano no contempla ningún alma que conforme, según el modelo aristotélico, el cuerpo que va generándose. El proceso de generación es de naturaleza química, y se pone en marcha a partir de la afectación de la materia femenina por el principio masculino. La excitación de la materia femenina por el principio masculino produce calor, esto es, agitación de partículas, que se expanden en el medio, extendiéndose y dilatándose, formando el corazón. El corazón es, por tanto, el principio de la vida, y el organismo va constituyéndose a medida que se forma más sangre, que provoca una mayor presión en el circuito mecánico que se va creando, formando así arterias, venas, órganos, etc. El sistema sanguíneo es fundamental para formar el cuerpo a través de una suerte de autoorganización de la materia. Vemos, entonces, que la función -la circulación de la sangre- precede al órgano - el corazón - y esta característica se extiende a toda la concepción genética cartesiana.

La posición mecanicista y estática a la hora de definir el cuerpo desde un punto de vista anatómico, lleva a Descartes a renunciar a la posibilidad de establecer la intervención divina en el caso de la generación. El proceso de auto-constitución de la materia prescinde de explicaciones que no sean puramente físicas y, por ello mismo, lleva a la propia anatomía mecanicista a sus propios límites. A pesar que Descartes afirme una y otra vez, tanto en su Descripción del cuerpo humano como en Los principios de la filosofía que la generación sigue un modelo estrictamente mecánico tal que es posible deducir la generación a partir de leyes físicas, su Generatio abre una brecha dinámica en el estatismo del mecanismo, poniendo en evidencia la aproximación entre autómata y organismo.

Si desde el paradigma del hombre mecanicista los órganos eran contemplados estáticamente como complejos mecanismos que desarrollaban una función determinada, la generación hace saltar por los aires el inmovilismo estático: los órganos se crean en un movimiento de flujo, bajo un modelo hidráulico, que resulta auto-finalista. Parece que en ese movimiento bullente de la sangre, del calor excitado de 
repente por el encuentro entre dos principios, para Descartes no se exprese otra cosa que el vértigo de la vida. La sangre se apelmaza, se contrae y expande y en su finalidad se coagula creando un órgano-mecanismo encargado de realizar y facilitar el dinamismo funcional, la finalidad del movimiento de flujo. El movimiento de los fluidos crea las condiciones de posibilidad para su dinamismo. Y el dinamismo es el principio mismo que anima todos y cada uno de los pasos de la embriología. El mecanismo, entonces, queda regulado en su función por la intención íntima de lo dinámico, queda ensombrecido por el exceso dinámico. La anatomía deja de ser el cuadro estático de la fábrica humana que Vesalio proponía, para ponerse en movimiento al dictado de la función dinámica, aunque todavía no podemos hablar de vitalismo, ni siquiera de un Descartes vitalista (Bibtol-Hespériès, 2002). El cuerpo ya no es resto, se encuentra formado y atravesado por un impulso que lo forma, lo conforma en cada uno de sus órganos, huecos, humores, nervios. $Y$, sin embargo, esa aparente finalidad de la vida no es atribuida al alma, a Dios, a leyes eternas, sino a una química enigmática de la materia. Descartes prefigura la mirada científica sobre la vida, anticipa la fisiología moderna centrada en la función a partir de las consideraciones sobre el movimiento de partículas minúsculas que se agitan desde el momento en que comienzan a vivir:

Quelqu'un dira avec dédain qu'il est ridicule d'attribuer un phénomène aussi important que la formation de l'homme à de si petites causes; mais quelles plus grandes causes faut-il donc que les lois éternelles de la nature? Veut-on l'intervention inmédiate d'une intelligence? De Dieu lui-même? Pourquoi naîtil des monstres? Veut-on y voir l'opération de cette sage déesse de la nature qui ne doit son origine qu'à

la folie de l'esprit humain? (Descartes, 1897b, p. 404)

Los errores, los monstruos, son errores químicos que no pueden ser atribuidos a leyes divinas. Al igual que la locura, afectación de los negros vapores de la bilis, no puede ser atribuida a leyes sobrenaturales. La naturalización de lo sobrenatural comienza a ser evidente, y comienza a planear en torno al concepto de lo irregular. De hecho, en el momento en que Descartes hable de la generación de los sexos, contemplará como una irregularidad en el camino entre función y órgano el caso del hermafroditismo (Descartes, 1897b, p. 504). Al igual que la locura, la monstruosidad es la irregularidad que se produce en un proceso dinámico que debería autorregularse. Un error de exceso de la vida misma ya naturalizada.

Todo parece ocurrir como si estuviesen entrelazadas la progresiva a aparición de la vida en el campo del saber y el paulatino borrado de la monstruosidad. Como si los monstruos, enfocados desde el sa- ber médico sobre la vida, sólo fuesen contemplados como errores. Descartes comienza a entender a los monstruos y los hermafroditas como un error de generación - no un error moral, ni siquiera una consecuencia de una procreación desajustada como era el caso de A.Paré-, es decir, como un error del proceso dinámico autorregulado de la vida misma. Es la vida la que hace a los monstruos errores, anormalidades (Canguilhem, 1980, p. 118). Y la prueba de tal cosa es el camino que en XVIII y en el XIX siguen tanto la fisiología como la monstruosidad.

Anatomical interest in monsters did not disappear; indeed, it intensified. Monsters became embedded in a larger embryological context, en listed as evidence for one or another ontogenetic theory [....] Thus by the early eighteen century, monsters had been normalized in the sense taht they were habitually related to a functional standard: the irregular. ... The new anatomical view of monsters corresponded to a particular view of the natural order as absolutely uniform and not subject to exceptions (Daston, Park, 1998, p. 208)

EI Siglo XVIII acelera la naturalización del monstruo desterrando, en su afán enciclopédico, todo resto de lo maravilloso. Queda expuesto el monstruo, signo ya vacío, a la mirada escrutadora de la medicina. La medicina, la ciencia, crecerá y se objetivará a partir de la fagotización de la rareza intrínseca al monstruo. Esa extrañeza que antaño fascinaba, signo de dios o del demonio, o incluso de la propia imaginación desbocada, queda ceñida para siempre y de un solo golpe a la estricta fijeza establecida por el orden de lo natural. Así lo evidencia el artículo de la Enciclopedia dedicado a los hermafroditas, que niega categóricamente su existencia asimilándolos a fantasías y supersticiones (Vázquez, 1997, p. 199). Aquello que no podía ser contemplado todavía como parte constituyente del orden natural y racional era, generalmente, desestimado, si bien no en todas las teorías médicas (Vázquez, Cleminson, 2011,p. 32). Los hermafroditas, hasta el siglo XIX, todavía se hurtaban a la mirada naturalizadora (Domurat, 2000). De este modo, la monstruosidad es progresivamente naturalizada o negada hasta su posterior naturalización. Es posible afirmar que el siglo XVIII es el siglo del gran rechazo de la monstruosidad, ejemplificada en la no asunción del hermafroditismo por parte de numerosas líneas teóricas ilustradas. El monstruo no naturalizado sigue poniendo en cuestión el orden, transgrediendo la identidad que se va conformando, interrumpiendo los saberes fundadores de subjetividad. Sólo en la medida en que el monstruo es utilizado para definir la norma, entendiéndolo como signo patológico, es posible asumirlo como error, como anomalía funcional. El monstruo, entonces, ha pasado de ser un signo de lo maravilloso a un desafío para la medicina, de una nada fantástica a una ano- 
malía funcional. Y, cuando el monstruo se convierte en una anomalía funcional, su figura se borra dejando libre el terreno para que se forjen nuevas figuras que dibujen el límite del nuevo orden de la vida: el hermafrodita, el loco, el perverso, el delincuente.

El extremo de esta naturalización de lo monstruoso la encontramos en el célebre Traité de Tératologie de G. Saint Hilaire, en 1837. La unión de la embriología epigenetista de Meckel y la anatomía comparada fundada en las series animales de Cuvier, permiten a G. Saint Hilaire establecer una nueva teratología que supondrá el fin de los compendios monstruosos. Saint Hilaire domestica todo resquicio de lo extraordinario en el monstruo sustituyéndolo por la anomalía, llevando a cabo una clasificación según las reglas del método natural, utilizando una nomenclatura metódica, logrando, en definitiva, que la monstruosidad revele el secreto de su existencia, de sus causas, de sus leyes: la anomalía explica la formación de lo normal, ya que "le pathologique est du normal empêché ou dévié» (Canguilhem, 1980, p. 180). La monstruosidad, ahora plenamente categorizada por la mirada positiva, nos ofrecerá la clave de interpretación y definición de lo normal a partir de la idea de que lo patológico es un camino errado que nos marca el correcto. Si obtenemos la desviación, obtenemos la norma. El monstruo se convertirá, entonces, una vez naturalizado, en un objeto del saber normal, del saber encargado de establecer las bases de la normalidad. Y, precisamente, es esta normalidad la que comienza a entreverse como base de la identidad. El monstruo, nos ha ayudado a comprender quiénes somos en tanto sujetos normales y disciplinados, posibilitando la extensión del saber médico al marco jurídico, es decir, la medicina legal.

Ahora bien, ¿cuáles son las condiciones de posibilidad del saber científico que han permitido que la ciencia traspase la opacidad del signo monstruo convirtiéndolo en el espejo anómalo de esos seres normales que somos? El nacimiento de la biología, esto es, la instauración de la relación entre el individuo y la vida se revela como fundamental a la hora de conseguir una naturalización total del monstruo. Porque el monstruo, considerado ya como anomalía que funda lo normal morfológico, confiere un valor total al éxito de la estructuración de la vida. El monstruo se opone a la vida en tanto representa una distorsión, un no acabamiento de la forma, un fracaso de la generación. El monstruo es la vida no viable. G. Saint Hilaire afirmaba: «Il n'y a pas d'exceptions aux lois de la nature, il y a des exceptions aux lois des naturalistes» (SaintHilaire, 1832, p. 37). La naturalización del monstruo implica el conocimiento positivo de las leyes de la vida, entendida ésta como un sistema cerrado y lógico de éxito generativo, que, a su vez, de manera implícita, casi subterránea, niega aquello contra lo que se levanta: un caos de «excepciones sin leyes» (Canguil- hem, 1980, p. 184). La vida como sistema positivo de saber excluye, por tanto, aquello que discute su reino positivo. Excluye aquello que la funda como sistema normativo, desterrando a la monstruosidad al reino de la anomalía, a partir de ahora elemento superfluo, excluido, encerrado, una suerte de anti-mundo poblado tan sólo de excepciones gimientes, encerradas a través del contorno del límite normativo que ellas mismas han inaugurado.

$\mathrm{Y}$, aquellos últimos elementos de la monstruosidad que todavía resisten irreductibles a la mirada positiva de la vida, como es el caso del hermafrodita, van a ser expulsados de la antigua caracterización teratológica $y$, progresivamente, mientras permanecen ignorados y negados, van conformándose en una nueva relación con la vida y los saberes. Los antiguos monstruos, todavía maravillosos, todavía inquietantes y perturbadores, desaparecen para siempre de la escena del saber.

\section{EL SILENCIOSO CAOS DE LAS EXCEPCIONES}

En 1561, para Pierre Boaistuau el monstruo era una ventana a lo maravilloso que jamás podría ser reducido a la positividad de la ciencia porque había algo en él que excedía las leyes humanas, esas leyes con las cuales los naturalistas intentaban dar cuenta de la realidad. Los monstruos y lo maravilloso, lo demoniaco y lo fantástico surca la Edad Media entera como un signo mudo de la incapacidad humana para hacerse con el mundo entero. No sólo con el mundo. También con nuestro propio cuerpo. Desde la perspectiva aristotélica y galénica mantenida hasta Vesalio, resulta imposible sacar a la luz positiva todos los secretos del cuerpo y del alma. El desarrollo médico y anatómico, entonces, tomó una senda particular. Separó el cuerpo del alma como único modo de entender los mecanismos íntimos del cuerpo. Y el monstruo nació para la mirada analítica, ya no como excepción de la ley divina, sino como mezcla, como error, como enigma a solventar. Lycosthenes, Paré y tantos otros comenzaron su particular categorización de la monstruosidad, en un intento de naturalizarla y concebirla bajo un prisma humano - racional, científico, positivo. Los trabajos médicos de Descartes constituirán un punto de inflexión fundamental a la hora de pensar el cuerpo como mecanismo sin referencia a ninguna instancia trascendental, posibilitando así el progresivo hundimiento de la mirada científica y positiva en generación de vida. El desarrollo de la fisiología permitiría naturalizar las anomalías monstruosas, tratándolas ya como una desviación de la norma, como la anormalidad que constituye la normalidad y, al mismo tiempo, es negada, excluida, encerrada: patologizada. El saber médico va poblándose de anormalidades, a la par que va extendiendo sus raíces jurídicas y legales hacia la noción de vida que aparece en el momento en que individuo y población se unen en el mismo cuer- 
po orgánico a través de la sexualidad. Y los antiguos monstruos, que ya tan sólo vivían en las antiguas teratologías, vuelven bajo el signo del hermafrodita para permitir el avance de la mirada médica, esta vez hacia la medicina social del XIX.

Desde esta perspectiva, aquellas silenciosas excepciones que la medicina legal había dejado en suspenso en su proceso naturalizador de la anormalidad, reaparecen con un nuevo sentido. El hermafrodita, que había sido negado en su existencia por la razón ilustrada, que había sido resuelto por el dictamen del experto en la medicina legal, vuelve a presentarse como un enigma a resolver: el de la identidad sexual. Es preciso delimitar los contornos exactos y positivos de la sexualidad, y, por lo tanto, apuntalar las desviaciones y anomalías que exhiben los hermafroditas. Porque será la sexualidad el lugar en dónde a partir del siglo XIX se va a buscar las verdades más profundas de los individuos a partir de una profusión de discursos científicos acerca de la relación identidad-sexo - con el psicoanálisis como uno de los momentos más evidentes de esta centralidad de la pareja verdad-sexualidad. La apertura de la vida que hay en el individuo permite un nuevo control sobre el cuerpo, sobre la verdad íntima de sí, al mismo tiempo que establece unos mecanismos de higiene y salud pública en virtud de su implicación con el organismo social. El hermafrodita, antiguo obstáculo borrado por la definición de su identidad sexual que llevaba a cabo el expertomédico legal, reaparece como lugar privilegiado donde medir la relación entre verdad y sexualidad. Habrá una verdad de la sexualidad, y esa verdad representará la identidad de un individuo que, en el siglo XIX, comienza a definirse primordialmente no por su cuerpo anatómico individual, sino por la unión entre su cuerpo y la especie.

A lo largo de esta breve historia hemos visto una desaparición de la monstruosidad maravillosa para dar pie a otro tipo de monstruosidad naturalizadaen la que ya no cabían los monstruos míticos, ni demonios, ni ecatónquiros, ni bicéfalos, ni sátiros. Durante la llustración los monstruos fueron borrados por la necesidad de hallar unas reglas de la naturaleza que no contuviesen excepciones. Las posibles excepciones fueron convenientemente categorizadas y naturalizadas hasta el límite de lo posible: locura, criminalidad, perversión. Cuando la medicina se abre a la sexualidad proponiendo una verdad del ser humano que lo vincule con la especie, la misma necesidad de delimitar la normalidad rescata la figura muda del hermafrodita, aplastada por el experto legal, y la interroga para que desvele la verdad de su sexo.

La monstruosidad, entonces, se nos aparece durante la modernidad no como una categoría fija que ha sido tallada sin titubeos por la ciencia médica. Más bien, podríamos entender a lo monstruoso como el silencioso caos de excepciones que se van oponiendo, sucesivamente, al orden natural establecido por los saberes modernos, particularmente médicos. Las excepciones, sin regla alguna, sin ley, sin racionalidad que las guíe, se presentan como contra-conductas, como herejías, como desplantes existenciales a las reglas de formación, de comportamiento, de existencia, de salud. Cuando el saber médico cambia, se afila, cuando hunde su mirada en un nuevo campo, modificando sus relaciones con el resto de saberes y con sus objetos, nuevas excepciones sin ley alguna pasan a poblar el caos de la anormalidad, el mundo otro dónde se agolpan, encerrados y dolientes, los fantasmas de una cultura.

El interés por la monstruosidad que ha traspasado toda la modernidad no es sino el interés por los fantasmas que constituyen el envés de la normalidad, el caos de excepciones que, encerrado y silenciado, acompaña a cada uno de las verdades producidas por los discursos sobre el saber. El hermafrodita, uno de los signos de la monstruosidad en el XIX, se borrará a su vez cuando el discurso sobre la sexualidad adquiera su estatuto positivo de verdad, propiciando un nuevo caos de excepciones que, en siglo $\mathrm{XX}$, tomará otros caminos cuando la medicina social pase a constituirse como una estrategia biopolítica y la noción de raza entre en juego. Porque, en definitiva, como afirma Bataille (Bataille, 1970, p. 229), la incongruencia que el monstruo y todas y cada una de las excepciones supusieron para la mirada del saber médico, se manifiesta a nivel individual en cada comportamiento distinto, excesivo, soberano. En la medida en que un comportamiento individual escapa a la norma común, el saber comienza a fijar el contorno de un nuevo monstruo, una nueva excepción, esto es, una subjetividad normalizada a prueba de excepciones. Excepciones, aparentes desvíos de la naturaleza, que posibilitarán toda la nueva economía saber-poder que constituye nuestro aquí y nuestro ahora. Aquí y ahora donde nuestros monstruos son historia.

\section{NOTAS}

1 "No es imposible ver huesos humanos [...] Pero si no has tenido la fortuna de verlos, haz una disección a un simio, quítale las carnes y en él fíjate con exactitud en cada uno de sus huesos. Entre los simios elige a los que sean más parecidos al hombre", (Galeno, 2002, p. 86). 


\section{BIBLIOGRAFÍA}

Ancet, Pierre (2006), Phénoménologie des corps monstrueux, Paris, PUF.

Bahuin, Caspar (1600), De hermaphroditorum monstrosorumque partuum natura, Frankfurt, Oppenheim.

Bataille, Georges (1970), "Les écartes de la nature". En: Bataille, Georges, Oeuvres Complètes, vol. I, Paris, Gallimard, pp. 228-231.

Bates, Alan (2005), "Early Modern Classifications of Monstrous Births", Social History of Medicine, 18 (2), pp. 141-158.

Bibtol-Hespériès, Annie (2002), Le principe de vie chez Descartes, Paris, Vrin.

Bichat, Xavier (1864), Recherches physiologiques sur la vie et la mort, Paris, Charpentier.

Boaistuau, Pierre (1561), Histoires Prodigieuses, Paris, Gabriel Buon.

Galeno (2002), Procedimientos anatómicos, Madrid, Gredos.

Canguilhem, Georges (1980), La Connaissance de la Vie, Paris, Vrin.

Canguilhem, Georges (2009), Estudios de historia y de filosofía de las ciencias, Buenos Aires, Amorrortu.

Daston, Lorraine and Khatarine Park (1998), Wonders and the Order of the Nature, New York, Zone Books.

Davidson, Arnold (2006), La aparición de la sexualidad, Barcelona, Alpha Decay.

Descartes, René (1897a), Oeuvres AT, vol. I, Paris, Léopold Cerf.

Descartes, René (1897b), Oeuvres AT, vol. IX, Paris, Léopold Cerf.

Descartes, René (1988), Correspondance avec Elisabeth, Paris, Flammarion.

Descartes, René (1999), Principios de Filosofía, Madrid, Alianza.

Domurat, Alice (2000), Hermaphrodites and the Medical Invention of Sex, Harvard University Press.

Foucault, Michel (1996), La vida de los hombres infames, Buenos Aires, Altamira.

Foucault, Michel (2007), Los anormales, Buenos Aires, FCE.

García Ballester, Luis (1976), Historia Social de la Medicina en España de los siglos XIII al XVI, Madrid, Akal.

Kant, Immanuel (1999), Crítica del Juicio, Madrid, Espasa Calpe.

Le Breton, David (1990), Antropología del cuerpo y la modernidad, Buenos Aires, Nueva Visión.

Liceti, Fortunio (1616), De mostrorum, Padova, Gaspar Crivellari.
Negri, Antonio (2008), Descartes político, Madrid, Akal.

Nogales, Amparo (2004), “Aproximación a la Historia de las Autopsias", Journal of Autopsy, vol. II (1), pp. 3-8.

Paré, Ambroise (1987), Monstruos y Prodigios, Madrid, Siruela.

Park, Katharine (2006), Secrets de femmes. Le genre, la génération et les origines de la dissection humaine, Paris, Les Presses du Réel.

Pichot, André (1993), Histoire de la notion de vie, Paris, Gallimard.

Peset, Jose Luis (1973), “La morfología biológica del barroco". En: P.Laín Entralgo, Historia Universal de la medicina, Madrid, Salvat, pp. 217-233.

Porter, Roy (2004), Breve historia de la medicina, Madrid, Taurus.

Roger, Jaques (1963), Les Sciences de la vie dans la pensé française du XVIII siècle. Paris, Armand Colin.

Saint-Hilaire, Isidore G. (1832), Traité de teratology, Paris, J.B.Baillère.

Schenk, Johannes (1608), Monstrorum Historia Memorabilis, Frankfurt, De Bry.

Tort, Patrick (1980), L'ordre et les montres: le debat sur l'origine des déviations anatomiques au XVIIle siècle, Paris, Le sycomore.

Turró, Salvi (1985), Descartes: Del hermetismo a la nueva ciencia, Barcelona, Anthropos.

Turró, Salvi (1989), "La evolución del pensamiento cartesiano", en R.Descartes, El mundo, Barcelona, Anthropos.

Váquez García, Francisco y Moreno, Andrés (1997), Sexo y razón. Una Genealogía de la moral sexual en España (Siglos XVI-XX), Madrid, Akal.

Vázquez García, Francisco y Cleminson, Richard (2011), “El destierro de lo maravilloso. Hermafroditas y mutantes sexuales en la España de la llustración", Asclepio, 63 (1), pp. 7-38 doi: 10.3989/ asclepio.2011.v63.i1.484

Vázquez García, Francisco y Cleminson, Richard (2013), Sex, identity and hermaphrodites in Iberia, 1500-1800, London, Pickering and chatto.

Vega, Maria José (1995), "La monstruosidad y el signo: formas de presignificación en el renacimiento y la reforma", Signa. Revista de Semiótica, 4, pp. 225-242.

Vesalio, Andrés (1960), De humani corporis fabrica, Bruxelles, Medicinal $\mathrm{H}$.

Wolfe, Charles (2008), “L'anomalie du vivant. Réflexions sur le pouvoir messianique du monstre", Multitudes, 33, pp. 53-62. 